\title{
¿DE LO BÉliCO A LO POÉTICO? EL POETRY SLAM Y SU LUCHA FEROZ EN DEFENSA DE LA POESÍA
}

From war to poetics. Poetry Slam's fierce battle in defence of poetry

\section{Diana CuLLELL}

UNIVERSITY OF LIVERPOOL (REINO UNIDO) diana.cullell@liverpool.ac.uk

\author{
RECIBIDO: 30 DE ENERO DE $2018 \quad$ ACEPTADO: 23 DE MARZO DE 2018
}

RESUMEN: El presente artículo pretende abrir un debate sobre las limitaciones que presupone fijar los slams poéticos como actos en los que su belicismo se subraya como el mayor aspecto definitorio y de mayor atracción para el público. Se analizarán artículos de prensa recientes y demás publicaciones para contraponerlos a un argumento en el que la posible competitividad de estos eventos poéticos se vincula a la audiencia que asiste a ellos, considerada ente esencial para el desarrollo de los slams. Todo ello se llevará a cabo con el apoyo de la escasa literatura que existe pese a su enorme éxito- alrededor de los slams en España y de los estudios académicos sobre perfopoesía realizados en el mundo anglosajón, y se explorará el slam como actividad vinculada a la risa o a lo carnavalesco. Asimismo, el artículo pretende analizar su naturaleza de fenómeno social y literario, y explorar el impacto y las repercusiones que el gran éxito del poetry slam puede acarrear para la poesía española contemporánea.

PALABRAS CLAVE: slams poéticos, oralidad, poesía, marketing, performance.

ABSTRACT: This article will discuss the limitations that presenting poetry slams as mainly warring and confrontational performances presupposes -even if it only obeys to marketing purposes. News items from recent newspapers and other publications on poetry slams will be analysed and linked to the audience, who plays a major role in the actual running of slams. The argument will be supported by the scarce literature on Spanish slam poetry that currently exists -despite the massive success of these performances- as well as the more abundant studies on the topic in the Anglophone world. It will also establish links between slams and carnival laughter. The article will look at slams as a literary but also social phenomenon, and it will draw some hypothesis on the impact and consequences that the success of poetry slam might have on Spanish contemporary poetry.

KEYWORDs: Poetry slams, orality, poetry, marketing, performance.

Cullell, Diana.

“¿De lo bélico a lo poético? El poetry slam y su lucha feroz en defensa de la poesía”. Kamchatka. Revista de análisis cultural 11 (Julio 2018): 239-257

DOI: 10.7203/KAM.11.11442 ISSN: 2340-1869

Monográfico LECTURAS DEL DESIERTO: NUEVAS PROPUESTAS POÉTICAS EN ESPAÑa 


\title{
INTRODUCCIÓN: EL POETRY SLAM
}

\begin{abstract}
Imagínese un escenario minúsculo y un micrófono. Al pie del escenario se agolpan jóvenes espectadores, sus chaquetas y bolsos. Detrás, en mesitas, con sus copas de agua tónica, cerveza o vino, el variopinto público en general charlando. Hace oscuro, un solo foco ciega en el escenario. El aire está cargado de expectación. Se siente las ganas de reír y compartir. La camarera sirve las últimas copas. De repente el silencio. Es el momento: el primer poeta sube al escenario, comienza el Slam (Herzog, 2011: 9).
\end{abstract}

El Poetry Slam se ha convertido en un fenómeno de gran fuerza en la España del siglo XXI. ${ }^{1}$ Esta rama de la poesía performativa, que cuenta en la Península con casi una veintena de grupos de slam, ${ }^{2}$ ha sido definida de muchas y variadas maneras, aunque la atención que ha recibido por parte del mundo académico hasta ahora ha sido extremadamente escasa (Cullell, 2015: 554). Con exposiciones que definen el poetry slam como una lucha entre poetas a golpe de micrófono, hasta aquellas que la califican de peligrosa juerga poética interesada únicamente en resaltar su vistosidad sin ningún tipo de atención a su calidad literaria (Hoffman, 2001: 49), los juicios son numerosos. Este artículo pretende abrir un debate sobre las limitaciones que presupone fijar los slams poéticos como actos en los que su belicismo se subraya como el mayor aspecto definitorio y de mayor atracción para el público: a partir de crónicas de prensa recientes y demás publicaciones, se analizarán tanto la presentación como la exposición de los slams para contraponerlas después a un argumento en el que la posible competitividad de estos eventos se vincula a la audiencia que asiste a ellos, ente esencial para su desarrollo. Los aspectos mencionados hasta ahora plantean cuestiones de clara importancia para el poetry slam, su continuidad y el impacto que puede tener su gran éxito en la poesía española contemporánea. El artículo intentará acercarse y ofrecer respuestas a tales preguntas: ¿el uso de lo bélico en crónicas y artículos de prensa responde únicamente a un interés publicitario? ¿Son conscientes las coaliciones de tal hecho? ¿Son culpables los propios grupos de slam de poner cierto énfasis en lo antagónico dentro del evento? ¿Podría considerarse que los slams están marketizando la poesía española contemporánea? ¿Oscurece esta posible marketización la exigencia de calidad literaria? ¿Ejercen los slams una nociva influencia en la poesía española del siglo XXI?

En el año 1994, durante el campeonato nacional americano de Poetry Slam celebrado en Asheville, Allan Wolf -el slammaster o maestro de ceremonias- acuñó la ahora célebre frase "The points are not the point; the point is poetry" (Los puntos son lo de menos; lo que importa es la poesía). La

\footnotetext{
1 El poetry slam es una actividad performativa en la que las varias actuaciones de los poetas -con un límite de 3 minutos por participante- se evalúan en un ranking. Un jurado de 5 personas es seleccionado al azar de entre los miembros del público, y procede a eliminar a los participantes en dos rondas siguiendo el funcionamiento de los Juegos Olímpicos (se desestiman la nota más alta y la más baja). En la ronda final, dos finalistas compiten uno contra otro para hacerse con un premio simbólico en forma de DVD, camiseta o libro. Véase el trabajo de Mex Glazner (2000) para una recopilación de la normativa existente alrededor de los slams, aunque debe notarse que en ocasiones y en espacios menos regulados pueden existir significativas variaciones.

2 En la actualidad existen 18 ciudades oficialmente adheridas a Poetry Slam España, la asociación sin ánimo de lucro encargada de gestionar la red nacional de grupos slams, así como de fomentar esta poesía, organizar el Campeonato Nacional de Poetry Slam en España y gestionar la representación del país en actos de Slam Poetry dentro y fuera del territorio nacional. En la actualidad, los grupos locales son: Barcelona, Bilbao, Cantabria, Ciudad Real, Granada, Hospitalet, Jaén, Lleida, Llobregat, Madrid, Mallorca, Murcia, Oviedo, Santa Coloma de Gramanet, Toledo, Valencia, Vitoria y Zaragoza.
} 
máxima de Wolf hizo mella, y pasó a convertirse casi en un mantra ampliamente utilizado por Poetry Slam Inc. y todas sus coaliciones dentro y fuera de Estados Unidos. La frase de Wolf lograba condensar en la mínima esencia el objetivo principal del slam: desestimar la importancia de la pugna por la puntuación más alta en el funcionamiento del evento, y destacar por encima de todo la poesía que presentan estos eventos. Sin embargo, y pese a la insistencia y repetición de la fórmula postulada por Allan Wolf por parte de la mayoría de asociaciones de slam en el mundo occidental, un gran segmento de la crítica y la prensa que ha estudiado o documentado el poetry slam ha preferido poner énfasis en el aspecto combatiente del evento poético. Cabe resaltar también que, pese a ser este hecho una excepción más que una práctica extendida, en algunas ocasiones incluso algunos slams han participado también de ello, ya sea a través de imágenes bélicas (irónicas o no) en los carteles de presentación, en el enfoque que se da a algunos poetry slams por parte del maestro de ceremonias, o durante las propias performances. ${ }^{3} \mathrm{El}$ aspecto competitivo -que no bélico- se ha enfatizado en numerosísimas ocasiones: tal es el caso de títulos de publicaciones como por ejemplo el estudio Poetry Slam: The Competitive Art of Performance Poetry, o incluso la propia definición que hace Poetry Slam Inc. de un slam: "poetry slam is the competitive art of performance poetry", y que presenta los slams como un ejercicio de competición artístico. Tyler Hoffman (2013: 202), siguiendo el aspecto competitivo del slam, lo equipara a un evento deportivo, y de manera muy particular establece fuertes vínculos con el mundo del boxeo o de la lucha libre, aspecto que se explorará más adelante en relación a la audiencia. De modo similar, cuando el poeta y activista lírico Holman define el formato del poetry slam como "las Olimpiadas de la Poesía" (2000: 16), ciertamente está identificando el evento literario con un acontecimiento deportivo de gran impacto social en el que se premia a un ganador por sus extraordinarias habilidades. Sin embargo, Holman prosigue su disquisición puntualizando que los slams son una fiesta o juerga de gladiadores en bares (16), con lo que por desgracia el propio poeta cae en la tentación de destacar el punto más crudo del evento, enfatizando lo que él entiende como un acto bélico entre poetas capaz de atraer la atención de un amplio público.

\section{PUGNAS SEMÁNTICAS Y LA PERFORMATIVIDAD DEL POETRY SLAM}

Un simple cotejo de las pocas publicaciones de slam en periódicos y revistas españolas que existen revela un claro énfasis en la pugna por hacerse con el galardón final. ${ }^{4}$ La semántica utilizada en las mencionadas crónicas es esencial para la presentación y difusión de estos eventos poéticos, y su carácter beligerante puede apreciarse ya en los títulos de varias de ellas: "Combate a verso libre" (S.S., 2013), "Batallas de rimas poéticas" (Arenas, 2011), "Batalla de versos a micrófono abierto" (Pérez, 2015), "El club poético de la lucha" (González Valero, 2013), o los incluso más sensacionalistas "Duelo de poetas en los bares" (Fernández, 2012) o "Duelo de

\footnotetext{
3 Como ejemplo véase el cartel anunciando el II Campeonato Slam Nacional de España celebrado en Jaén el año 2012 [último acceso 19 de enero de 2018].

${ }^{4}$ Cabe resaltar también la monotonía de los trabajos que ofrecen un recuento de los poetry slams, como si se tratara simplemente de una crónica que va actualizándose de semana a semana, de mes a mes o de año a año. La falta de originalidad y la simple repetición de los reportajes podría indicar una falta de interés, o una propensión a redundar simplemente en lo ya dicho para difundir algo que se considera de interés moderado.
} 
versos" (Gallardo, 2015). En las crónicas o reportajes mencionados, los slams se presentan como simbólicos cuadriláteros en los que los poetas se enfrentan los unos a los otros: "[a]sí se suben 'los slammers' a los escenarios madrileños para medir sus fuerzas a golpe de poesía" (Pérez, 2015). Los rótulos usados pueden obedecer al dramatismo que caracteriza a los titulares de la prensa actual, y a su razón de ser como herramienta de marketing en un mercado sensacionalista: "newspapers actively compete for readership. To win readers' attention, newspapers have an incentive to publish sensational stories, namely attention-grabbing, speculative news with broad readership appeal. Understanding this incentive is important" (Ahern y Sosyura, 2015: 2020). ${ }^{5}$ Asimismo, en su discusión sobre el sensacionalismo, Margarita Antón Crespo lo califica de una "alteración en la presentación de los hechos noticiosos, favoreciendo los aspectos más sonoros y espectaculares y que logran un impacto sobre el receptor" (2015: 39), definición que se adapta perfectamente a los titulares mencionados sobre el slam y que lo convierten también en un producto mucho más marketizable.

Resulta interesante comprobar que existen también sugestivas contradicciones alrededor de los poetry slams en los artículos citados. Por ejemplo, Susana Pérez presenta el slam mensual de Madrid en términos de un "combate", en el que los poetas "se ven las caras" en un escenario sobre el cual se da inicio a una "lucha". No obstante, en la misma crónica, la periodista cita a Silvia Nieva, organizadora del evento, en un testimonio que parece cuestionar el tono dado a la noticia y en la que el slam se presenta no como una competición sino como "una excusa para que el público asista a un recital dinámico" (Pérez, 2015). La periodista cierra la pieza afirmando que el slam es una cita que reúne a "personas con una pasión común: la poesía" (Pérez, 2015), lo cual parece desestimar, al menos de manera parcial, su concepción inicial del slam como un simple y mercantil combate. De manera similar, Victoria Gallardo llama la atención en una de sus piezas periodísticas con un encabezamiento de lo más provocador ("Duelo de versos"), y con una afirmación algo paradójica en el cuerpo del texto: "Un puñado de rimas memorizadas o garabateadas en un papel y tres minutos son las únicas armas de las que disponen para medirse con sus rivales ante el micrófono, en un duelo donde no hay vencedores ni vencidos. Sólo poesía" (2015). Su observación parece jugar con la idea del slam como actividad lúdica, pero la mezcla de términos semánticos como "medirse", "rivales" o "duelo" problematiza una clara interpretación. De esta manera, la semántica usada parece responder a lo que Conboy identifica en su estudio sobre la prensa amarilla británica -aunque no sean estas fuentes parte de la prensa amarilla puede extrapolarse que su propósito es el mismo-, como lenguaje mitificador: "the language of the contemporary tabloids needs to be immediate, contemporary, mythological in the sense that Barthes (1974) meant when he talked of myth as a device which extracted events from their historical and political contexts" (2006: 11). En este sentido, el lenguaje utilizado para referirse a los poetry slams "is reaching its own tradition of metaphor, word play, categorization and

\footnotetext{
5 Para un interesante estudio sobre el periodismo y los cambios que ha experimentado a lo largo de su historia véase el trabajo de Martin Conboy Journalism: A Critical History (2004). Resulta de particular interés la cita de Bob Franklin que esta obra incluye: “Journalism's editorial priorities have changed. Entertainment has superseded the provision of information; human interest has supplanted the public interest; measured judgement has succumbed to sensationalism; the trivial has triumphed over the weighty; the intimate relationships of celebrities, from soap operas, the world of sport or the Royal family are judged more 'newsworthy' than reporting of significant issues and events of international consequence. Traditional news values have been undermined by the new values; 'infotainment' is rampant (1997:4)" (199).
} 
compression of narratives" (2006: 15) y hace uso del sensacionalismo, presentando una idea algo distorsionada de estos eventos poéticos a todos esos lectores que no hayan presenciado nunca antes un poetry slam.

Las mismas imágenes, aunque con un énfasis más prevalente en el aspecto competitivo de los poetry slams, se extienden en antologías y estudios sobre ellos, muchos de los cuales establecen también interesantes vínculos entre este movimiento poético y una tradición oral ya establecida que incide igualmente en rasgos de competición: "while slams have inaugurated some folks into a recent understanding of poetry as a competitive sport [...] verbal competition has a respectable history in many oral traditions" (Damon, en Martínez Cantón, 2012: 394), refiriéndose principalmente a un torneo literario a la manera clásica de las justas o certámenes literarios (Laura, 2012; Martínez Cantón, 2012: 394; Fanjul, 2013; Gutiérrez, 2014). El slam entendido como un retorno al pasado y no un arte completamente nuevo (Boudreau, 200; Chivite Tortosa, 2012; García Villarán, 2012; Iglesias Lodares, 2012; Manzano Franco, 2012; Mezquita y García Villarán, 2012; Teuma, 2015) encuentra en el aspecto competitivo su punto de apoyo más fuerte, pudiendo argumentar que las justas o los certámenes literarios del Siglo de Oro no son simples analogías sino la simiente o raíz de los slams contemporáneos. Cabe recordar que las justas poéticas fueron certámenes literarios de gran popularidad en la península ibérica durante los siglos XVI y XVII, y se celebraban durante festividades religiosas y celebraciones reales, para más tarde extenderse también a fiestas de carácter popular. Con el paso del tiempo, la fama de las justas se extendió, y fueron objeto de críticas tanto negativas como positivas por parte de numerosos autores -la mayoría de impugnaciones se referían al escaso valor literario de los poemas premiados (argumento que los detractores del poetry slam también han esgrimido con frecuencia en la actualidad) o a la falta de innovación debida a una temática y forma métrica que habitualmente dictaba la normativa de cada justa. ${ }^{6}$ Al igual que los slams en nuestro tiempo, las justas poéticas eran acontecimientos que provocaban curiosas respuestas sociales, al tiempo que unían robustamente a una comunidad. Abascal Vicente presenta las justas como:

Todo un espectáculo que ha llamado la atención por la complejidad de la respuesta social que provocaba (varios días o semanas de fiesta con una gran participación), por el grado de elaboración artística de esa respuesta [...] y porque la poesía aparece por todas partes como ordenadora de esa composición. Pese a que los poemas que concursan son productos de la escritura, se han visto rasgos de oralidad en los textos por estar concebidos para una lectura en voz alta, y se ha visto, sobre todo, la oralidad espectacular del acto final en el que se resuelve el concurso, con la gente congregada en un escenario fastuoso (un local noble profusamente decorado), los jueces sentados en un lugar eminente y una única persona designada para hablar que hace una introducción chistosa, lee un discurso sobre el tema del certamen, lee los poemas seleccionados y la sentencia, a veces versificada, en medio de notas jocosas y encomiásticas, todo ello con pausas musicales que revisten el acto de solemnidad (Abascal Vicente, 2004: 11).

Los paralelos con el poetry slam resultan obvios, no únicamente en cuanto al funcionamiento y estructura del acto poético en sí -ambos cuentan con la presencia de un maestro de ceremonias

\footnotetext{
${ }^{6}$ Un ejemplo de la relevancia y controversia de las justas poéticas en esa época puede encontrarse en la mención que se hace de ellas en El Quijote: “y con todo el mal cariño que muestra tener a la poesía de romance, le tiene agora desvanecidos los pensamientos el hacer una glosa a cuatro versos que le han enviado de Salamanca, y pienso que son de justa literaria" (Cervantes Saavedra, 2004: 633).
} 
y de gran resonancia colectiva (Osuna, 2004: 35) - sino también por el rasgo de oralidad intencionada que impera en la preparación de los textos que serán leídos, lo cual determinará en gran manera el modo en el que el público recibe el poema. La destreza de los poetas a la hora de recitar una composición durante un poetry slam ha sido también motivo de crítica y recelo entre varios estudiosos por considerar la performance más válida que la poesía en sí: “Slam poetry, it’s true, often does a healthy business nowadays. I deeply admire the efforts of slam to popularize their work beyond the college campus, but let's make a crucial distinction: much slam poetry depends not on its text, as poetry that merely sees print, but on sheer acting ability" (Kennedy, 1997: 70). Como afirma Julia Novak (2011: 19), con frecuencia se han considerado la oralidad y la escritura como dos formas de expresión cultural totalmente opuestas dentro de la ampliamente discutida Gran División (Ong, 1997). Pese a que el debate sobre la Gran División fue abandonado hace ya décadas, aún pueden observarse huellas de la dicotomía entre lo oral y lo escrito tanto en la práctica poética como en su crítica (Novak, 2011: 18). En sus estudios sobre oralidad y escritura, Novak identifica la permanencia de la división en, por un lado, la idea del poema escrito visto como un artefacto estable, tangible y atemporal, el cual existe al margen de su contexto situacional. Al otro lado del espectro se encuentra el poema performativo, entendido como un proceso efímero o temporal que depende de su ejecución y que desaparece inmediatamente en el tiempo, muchas veces considerado como una simple variante del original en papel (19). Estas premisas no han hecho más que dificultar el estudio del slam como producto cultural digno de atención crítica y de razonamientos reflexivos: "[n]uestra sociedad, tan apegada a la escritura, parece en muchos casos sentirse incómoda con las performances poéticas no grabadas, que no pueden reproducirse posteriormente" (Martínez Cantón, 2012: 391). Obviamente, ninguna grabación visual o auditiva puede igualarse a la experiencia de presenciar en vivo y en directo una sesión de poetry slam, pero en los últimos tiempos se han presentado proyectos muy interesantes que ha intentado subsanar este menoscabo, como por ejemplo la colección Palabreadorxs, de la editorial Amargord, que combina el libro en papel con un CD. Sobre la poesía en vivo, Novak intenta sintetizar la experiencia afirmando que "live poetry is characterised by the direct encounter and physical co-presence of poet-performer and audience. This encounter occurs in a specific spatio-temporal situation, and it is this definite 'situatedness' that constitutes the performance's essence as shared experience" (2011: 173). La clave, entonces, se encuentra en esta experiencia compartida, y no individual, que ofrece un acto poético en vivo, y que resulta prácticamente imposible capturar a través de audios o vídeos. Mientras un libro puede guardarse en las estanterías de una biblioteca durante décadas o incluso siglos esperando el momento de ser redescubierto y leído, prosigue Novak, la poesía performativa:

is marked by the simultaneity and collectivity of its production and reception. It depends on the common effort of poet and audience to make it happen in the here and now, and on the direct influence they have on each other by way of their physical presence. Audience members may be provoked to smile, sigh, or clap enthusiastically, by the poet as well as by each other. They may in turn provoke a poet to alter the tempo of his/her delivery. They may prompt him/her to change the order of his/her pieces, or to skip a line. They may drown out parts of a poem in loud laughter and request that other poems be repeated. A different audience means a different performance, as anyone who has seen the 'same' theatre performance or heard the 'same' poem twice on different occasions might testify (2011: 173). 
En eventos como estos, entonces, el papel del público resulta completamente esencial a la hora de estudiar su funcionamiento. Los miembros de la audiencia, que no son ya simples espectadores sino participantes o incluso co-autores o co-productores, deben ser incluidos como un factor más dentro del poetry slam. Se trata este de un proceso de doble dinámica: "the audience does not only react to the poet-performer: audience members also react to each other's presence" (Novak, 2012: 374). En su estudio sobre la semiótica del teatro -y muy fácilmente extrapolable al mundo del slam por los rasgos de performatividad que ambas actividades comparten-, Keir Elam (2002: 86) describe tres efectos claves para una respuesta homogénea del público en la comunicación entre espectador y espectador: la estimulación (un estallido de risa entre parte del público provocará más risas entre la audiencia); la reafirmación (los espectadores ven sus reacciones corroboradas por los demás); y la integración (se promueve una unidad entre la audiencia, en la que se desestiman funciones a nivel individual).

\section{ANÁLISIS POÉTICO-PERFORMATIVO Y EL PAPEL DEL PÚBLICO}

Probablemente ninguna otra actividad poética oral requiere una participación más elevada por parte del público como un slam: los varios miembros de la audiencia se retroalimentan los unos de los otros y sus respuestas y reacciones dependen en gran manera de las de los demás; por esta razón, el papel de juez del que disfrutan únicamente cinco personas entre los asistentes se convierte en algo más general y extensivo, palpable en la performance. Encontramos aquí a una audiencia que presta toda su atención al poeta que sube al escenario (Gregory, 2008: 67), con el que tiene un contacto de lo más directo. ${ }^{7} \mathrm{Y}$, obviamente, los poetas hacen uso de esta conexión inmediata y se nutren de todas las ventajas que esta aporta. Es una práctica usual entre los slammers subirse al escenario y encabezar su actuación con una captatio benevolentiae o una frase jocosa que permita hacerse con el aprecio directo del público que le juzgará colectivamente. A estas prácticas iniciales suele también acompañarle la contextualización del poema, y, en numerosas ocasiones, una exhortación directa a participar activamente en los versos que se recitarán. Tal es el caso, por ejemplo, de la recitación de "iVámonos!”, de Pablo Cortina. Cortina, slammer usual en los varios circuitos de España, representante nacional en campeonatos europeos y también organizador de Poetry Slam Madrid, ha recitado el mencionado poema en varias ocasiones. ${ }^{8}$ Resulta altamente interesante resaltar que la lectura de "iVámonos!" ha conseguido resultados muy diferentes entre sí en varios de los eventos en los que ha recitado, poniendo de relieve que cada performance tiene una dinámica y un funcionamiento distinto, y es un ente en sí misma. La diferencia estriba mayoritariamente - en este caso particular- en cómo el público se ha implicado en el desarrollo del poema cuando el poeta los ha animado a intervenir en la

\footnotetext{
${ }^{7}$ Citando a Abercrombie, Novak considera que el público presente en un acto poético en directo debe clasificarse como "audiencia simple", en contra del público de la televisión, que es una "audiencia masiva". La "audiencia simple" se caracteriza por su alto nivel de atención, cierta naturaleza ceremonial y una comunicación más directa entre autor y receptor que además suele ocurrir en un espacio público (Novak, 2011: 194).

8 El poema puede también encontrarse en versión escrita en su obra Contra los 'Slammers': 12 partituras, un poema y un discurso (2016), junto a un sugestivo discurso sobre el slam desde el punto de vista de alguien íntimamente ligado a él aunque manteniendo cierta objetividad.
} 
composición. 9 De las varias ocasiones en las que Cortina ha escenificado el poema, destaca sin duda alguna la del slam mensual de Madrid de septiembre de 2014, en el que el poeta se hizo con el galardón final. En dicho evento, Cortina salió al escenario haciendo uso de una captatio benevolentiae (argumentando que había perdido la voz ese día), y con grandes gestos animó al público a que abriera el poema con él -siempre en primera persona del plural- declamando "monos, monos, monos, monos". Esta invectiva asentó definitivamente el tono del poema que recitó seguidamente, al tiempo que imitaba los chillidos de una manada de simios, protagonistas metafóricos y simbólicos de la composición y parte esencial de los giros semánticos, el ritmo, los juegos de palabras y el tema de "iVámonos!". El acto de animar al público a recitar con él -y que marca una clara diferencia en la recitación de "iVámonos!" en las performances de Cortina- es un ejemplo perfecto de uno de los principios esenciales que gobiernan la respuesta homogénea de un público según Elam: el de la integración. A través de la puesta en común de "monos, monos, monos, monos", se logra una unidad absoluta como audiencia, formando un todo que deja de lado al espectador a nivel individual. Cortina, entonces, forja la mencionada comunicación entre espectadores al inicio del poema con marcadas expresiones deícticas, señalando al mismo tiempo y de manera muy ingeniosa la importancia de un "nosotros", primera persona del plural, en toda la composición:

\author{
¡Vámonos! \\ ¡Yo soy monórkico! \\ ¡Qué nos gobierne un mono! \\ Un plátano sería su cetro, un árbol \\ sería su trono. \\ Que nos gobierne un mono. \\ ¡Vamos a la monorkía! \\ ¡Vámonos! ¡Va, monos! \\ Fundemos un nuevo partido mono \\ y llamémoslo Va, monos, \\ llamémonoslo \\ ¡Vámonos! ¡Va! \\ ¡Monos! \\ ¡Vámonos! \\ ¡Vámonos por las ramas! \\ ¡Vámonos por el morro! \\ ¡Vámonos por donde nos venga en gana! \\ ¡Remoloneemos entre lianas! \\ ¡Remonoloneemos!
}

Dejemos crecer la selva por debajo de los monos.

¡Hay que ilegalizar Podemos!

\footnotetext{
${ }^{9}$ Para facilitar que el lector de estas páginas acceda en parte a la escenificación del poema -aunque esta no pueda igualarse a la experiencia de encontrarse inmerso al acto en directo-, pueden visionarse algunas grabaciones de varios slams en los que Cortina leyó el mismo poema, y en los que se pueden observar distintas aunque parciales reacciones a la performance: https://www.youtube.com/watch?v=pUfbSHq4RXI, o https://www.youtube.com/watch? $\mathrm{v}=\mathrm{EUFzC4jq8Bg}$ [último acceso 19 de enero de 2018].
} 
¡Podemos no, hay que dejar crecer todo!

Que el tallo crezca, la flor de lys florezca, la enredadera enrede, que al suelo llegue de cuando en cuando un átomo de nada

y se lo repartan entre todos.

$¡$ Hay que enredar!

Que nadie vea qué todo es ese.

No digas todo, di tó, como mucho,

ino aprendas a leer, no aprendas a pensar,

no aprendas, quédate abajo, subnormal!

Sub-lo normal.

¡No subas, sé sub,

no digas todo, di tó como mucho, sub,

di

tó.

¡Quédate ahí! ¡Mira qué mono tó!

Monorkía.

Parlamonomento.

Presidente del Gobiérmono.

Tribunal Suprémono.

Demonocracia,

desinformonoación,

capitalísmonomonomonomonomonomonomó

Monosterios, monostros,

monondial de fútbol, monondial de balonmono,

pormonografía...

Monomentos conmemonorativos de nuestra legitimidad monórkica...

¡Un mono ecuestre en la Puerta del Sol!

¡Un mono ecuestre en la Plaza Mayor!

Un mono emérito campechámono,

un mono monolítico, monodélico, con estudios,

con barba y ojos azules,

sin barba y ojos azules,

un mono que contrae matrimono con una princesimia asturiámona

y tienen la niña más mona del mundo

¿Leo? ¡Nor! Yo soy monórkico, no leo.

¡Que nos gobierne un mono!

¡Vámonos! ¡Va, monos!

Que el himmono de España sea

"Yo soy el rey del jazz a go-go,

el más mono rey del swing,

más alto ya no be de subir

y eso te hace sufrir"

¡Subvencionémonos! ¡Retransmitámonos!

¡Autoalabémonos, lucrémonos!

¡Amémonos mientras los súbditos nos aclaman,

nos aman, nos amamantan!

[mamo] 
" $A$ tu salud, -súbdito-

dímelo a mí, -súbdito, di tó, di-

si el trono a mí,

me lo traerias tú!"

(Cortina, 2016: 21-24)

Las risas que estallaron entre el público del slam mensual de Madrid cuando Cortina, a modo de maestro de ceremonias, ordenó poner punto y final a la proclamación en común de "monos, monos, monos, monos", forman también parte de la estimulación a la que se refiere Elam -cuando las carcajadas de algunos espectadores provocan otras-, y de la reafirmación durante la cual los espectadores se reafirman en las reacciones (carcajadas) de los demás. Podemos observar cómo, a lo largo de todo el poema, Pablo Cortina provoca y espera la reacción o las risas cómplices del público, haciendo referencia en todo momento a la realidad política y social con la que se identifican los miembros de la audiencia -destacan especialmente las reacciones a la mención de la familia real, o del partido político Podemos. Los juegos semánticos y el uso de neologismos crean puntos álgidos de humor en el poema, así como también lo hacen los versos cantados que parafrasean fragmentos de la canción "Quiero ser como tú", de El Libro de la selva, y establecen perspicaces paralelos con los personajes del poema. De modo similar, las pausas dramáticas durante las que Cortina mira a la audiencia y aguarda pacientemente su reacción contribuyen tanto al humor de la performance como a la alimentación de una relación totalmente simbiótica entre poeta y público. De hecho, el propio Cortina, en su argumentación sobre el poetry slam incluída en Contra los 'Slammers': 12 partituras, un poema y un discurso, no duda en afirmar que en el slam, la confianza y el papel que se da en el evento al público no son sino "una muestra de respeto por la audiencia" (2016: 85). El contacto visual y oral entre espectadores y poeta favorece igualmente la creación de un "nosotros" colectivo que permite entablar un excepcional vínculo con el público. La propia conjugación de los imperativos en primera persona del plural (estrategia a la que tanto recurre el poema) hace juego a la recitación formando el término "monos" en cada frase y armonizando el ritmo y la fluidez del poema tanto en su forma como en su fondo. El cambio de un yo primera persona del singular -el poeta que carece de vOz para recitar- a un nosotros primera persona del plural que participa y se convierte en protagonista del poema hace que se integre a la audiencia como parte clave de la performance desde su mismo inicio, a modo de grupo único - $\mathrm{O}$ a modo de la sociedad que desea ser gobernada por el mono del poema. El uso de la primera persona plural es, además, un poderoso deíctico en la poesía performativa, ya que según Novak, "a sense of direct audience address will also depend on the poem's deixis. Apostrophe - the use of the pronoun "you" - has a much greater effect in live poetry, where "you" finds a real-life target and can be understood as implicating the present audience in the speech act" (2012: 375). Con la desaparición de un yo poético absoluto, Cortina está solucionado, al menos en parte, una de las cuestiones de más interés en relación a los vínculos que se establecen entre autor, actor y voz poética durante el acto performativo. En un espectáculo teatral, al contrario que en un slam, el actor representa un papel específico y concreto, y con ello se establece una clara distancia entre la persona que está encima del escenario y el personaje al que representa en esos momentos. En un slam poético, no obstante, dicha separación no existe o bien es extremadamente tenue, ya que los espectadores no pueden distinguir entre el poeta que escribió la composición, la persona que la recita, y el yo poético que aparece en el 
poema. ${ }^{10}$ Con el ya mencionado contacto oral y visual entre Cortina y el público, y el recurso a su participación en la recitación del poema, el poeta cede su lugar de protagonismo para incluir al público como casi un autor más del poema, sin cuya aportación la composición no tendría sentido. ${ }^{11}$

La importancia del público se extiende más allá de su aportación a la performance, y cruza esferas para adentrarse incluso en la concepción del poetry slam como producto cultural. Como se ha mencionado antes, Tyler Hoffman destaca un interesante parecido entre los poetry slam y los espectáculos de lucha libre -algo que se reprodujo en el Green Mill a lo largo de 1986, cuando la slammer Anna Brown subía al escenario como Rambolina, una bailarina armada y vestida con un tutú de camuflaje (en una especie de parodia del hipermasculinizado personaje de acción Rambo), para recitar contra Jean Howard, también vestida con hombreras de cuero y guantes de piel con púas metálicas. Cabe resaltar que una visión muy similar se propone también en el vídeo y material promocional para el ya citado II Campeonato Slam Nacional de España. ${ }^{12}$ No obstante, para Hoffman la correlación entre el slam y lo bélico que se establece aquí funciona en términos del público, y no como ejercicio deportivo en sí. Según el catedrático americano,

Wrestlers elicit responses from the crowd and react to the yelled comments of fans seated nearby; fans are encouraged to support their heroes by cheering loudly when they are in a temporarily compromised position. On television one notices that the audience at these events is lighted as deeply as possible, indicating that they, too, are conceived of as performers in the ritual. In this way, communitas is enacted, with audience members brought closer together through their common understanding of the events transpiring in the ring. But if American professional wrestling is a "dramatic ritual... communicated through the use of instrumental symbols, composite symbols, and stereotypes whose meanings act to reinforce cultural myth and to reinforce in-/ equalities," the dramatic rite of the slam seeks to dismantle cultural myths of identity and to abolish (if temporarily) inequalities. In effect, it works to escape from its own status as commodity spectacle (Hoffman, 2013: 202-203).

Para Hoffman, entonces, el poeta es quien intenta provocar, en primer lugar, una reacción entre la audiencia. Una vez se ha obtenido una respuesta por parte del público, aclara Hoffman, la audiencia pasa a formar parte de la performance, no únicamente en calidad de juez como sería el caso de los cinco miembros seleccionados para juzgar el slam, sino también como fragmento de

\footnotetext{
10 Ahondar en el ser que está siendo performativizado es algo que escapa a los parámetros de este estudio, y todo lector interesado en el tema puede referirse al estudio de Julia Novak (2012: 363-372).

11 Novak destaca también el hecho de que en un evento poético en directo la experiencia de la audiencia no depende únicamente de la actuación o el recital de los poetas, sino que obedece en gran manera a la propia audiencia y a la dinámica que se establece entre los asistentes (2011: 198). Este punto nos revierte nuevamente a los tres elementos que Keir Elam cita como claves para una respuesta homogénea: la estimulación, la reafirmación, y la integración (2002: 86). Es precisamente la afinidad entre el público y los tres elementos homogeneizadores aquello que resulta más difícil de ilustrar y detallar en un estudio como el que ocupa estas páginas, y aquello que es prácticamente imposible de retener en una grabación visual o auditiva del slam. Novak advierte también sobre una gran dosis de "contagio" entre las reacciones de los varios individuos del público, y de cómo esta puede fácilmente influir en la interpretación o estudio del propio investigador (2011: 198).

12 Véase el citado vídeo en el siguiente enlace. [último acceso 19 de enero de 2018].
} 
un todo que ayuda a guiar la actuación y a erradicar desigualdades entre el poeta y el púbico.13 Asimismo, existen pocas maneras más eficaces de animar al público -aparte de la exhortación directa- que la de presenciar un acto del que va a salir un único ganador y en el que los espectadores deben inclinarse por un poeta u otro. A parte de su eficacia en este ámbito, cabe mencionar que la competitividad y el juicio de la audiencia inciden de manera muy positiva en un filtro de calidad literaria para los slams - por muy rudimentario y poco ortodoxo que pueda parecer este cedazo-, y rebaten el recelo expresado por numerosos críticos ante la calidad variable del poetry slam (Barber, 2000: 379; Arenas, 2011; Berger, 2012: 62; Cullell, 2015: 55). Cabe resaltarse además, que esta criba ostena un funcionamiento a doble nivel que repercute en la calidad tanto de la poesía como del público que la aprecia: "el público participa, siente que su opinión también se escucha, sabe que lo que diga se llevará a efecto. Aprende, por tanto, a juzgar con más responsabilidad. Quiere saber más para la próxima vez. Lee más poesía, entre uno y otro slam" (Cortina, 2016: 81). En este sentido, puede incluso vincularse este deseo de enriquecimiento y perfección por parte de público y poetas a la propia competición, aunque Cortina asegura que "en el slam se compite abiertamente, con lo que la competición se desactiva" (81). En cualqueira de los casos, y al igual que en los espectáculos de lucha libre, el aspecto competitivo permite una communitas que une a los espectadores de manera muy firme. Sin embargo, un análisis más profundo revela que la anulación de desequilibrios en la performance y la marcada importancia que se le atribuye al público en estos eventos desestabilizan la concepción de esta forma de poesía como una simple mercancía cultural que vende fácilmente dado su atractivo y la proyección que se le ha dado, para convertirla en un movimiento casi social y de fuertes repercusiones para la poesía española contemporánea. En este sentido, "the slam lives a double life: even as it appeals to the masses through a slick commercialism, much of its poetry defines itself against commodification, and often in sharply satirical ways" (Hoffman, 2013: 205). En la performance de "¡Vámonos!" puede apreciarse cómo Cortina anima a los espectadores a participar en el poema desde el principio, cultivando una reacción que continuará a lo largo de la recitación y le ayudará a fomentar un sentimiento de comunidad e igualdad entre el público que incluye también al propio poeta -víctima de posibles risas y al poder de la audiencia en cuanto a la puntuación final. Cabe destacar que los slams suelen tener lugar en espacios de marcado carácter social, como podrían ser cafés, bares, bares-librería o salas públicas -casi siempre alejados de los círculos literarios oficiales o de prestigio-, los cuales aportan una atmósfera íntima y propicia para una unión con el público. En estos ambientes se crea una dinámica muy particular que determina ya en parte la relación que se establecerá con el público asistente. Este público es, dado el espacio en el que se encuentra, mixto: algunos de los asistentes están interesados en los slams como evento literario, pero también pueden ser individuos que presencian el evento como parte de una actividad social más amplia, como una noche de diversión con amigos y conocidos. La naturaleza de un público mezclado, debe destacarse, amplía el radio de alcance del slam poético. Este radio contribuye a la creación de nuevos seguidores -espectadores que al encontrarse cara a cara con la poesía descubren una nueva pasión- y lo que algunos han considerado también la emergencia de nuevos creadores -gente que sube al escenario a recitar

\footnotetext{
13 Cortina resalta un punto similar cuando marca claras distinciones entre el papel del público en los slams, y aquel que tiene en deportes como el fútbol (al que califica de "absolutista"), en los que sus reacciones no tienen ningún tipo de influencia sobre el juego y su desenlace final (Cortina, 2016: 81-82).
} 
animado por las actuaciones que ha presenciado en anteriores ocasiones, sin considerarse necesariamente poeta en toda regla (Arenas, 2011; Cortina, 2016: 80-85; Laura, 2012; Quinto, 2013: 199; Cullell, 2015: 554). No debe sorprender, entonces, que en un ambiente en el que reina lo social como punto de encuentro domine también una poesía de temática política, social e históricamente comprometida, que puede ser incluso anti-sistema (Laura, 2012; Gutiérrez, 2014; Gallardo, 2015). Aunque los temas son del todo imprevisibles en un slam y no vienen marcados por el slammaster, sí es común observar una proliferación de la temática amorosa -siempre presente en el género poético-, y una insistencia constante en el paro, la crisis, la deshumanización y la política del país, algo que salta también a la vista en el poema de Cortina aquí analizado. Todo ello, no obstante, se lleva a cabo con grandes cantidades de humor, y sin ceñirse a una estilo o temática absolutista.

Los estallidos de risa y humor que fomenta el slam para hacerse con el beneplácito del público han generado numerosas comparaciones entre este evento poético y la cultura carnavalesca. El slam puede, sin duda alguna, tener ciertos aspectos carnavalescos, y es posible establecer fructíferos paralelos entre el poetry slam y las ideas sobre la risa y el carnaval que desarrolló Mijaíl Mijáilovich Bajtín en su obra La cultura popular en la Edad Media y el Renacimiento. El contexto de François Rabelais (2003). Bajtín dividía la cultura cómica popular en tres categorías principales aunque estrechamente relacionadas entre sí: formas y rituales del espectáculo que incluían actos y festejos representados públicamente; obras cómicas verbales de base oral y escrita; y formas y tipos de vocabulario familiar y grosero tal y como insultos o juramentos (Bajtín, 2003: 4). Las mencionadas categorías encuentran una réplica casi perfecta en el slam y su performance en la España del siglo XXI. Cabe recordar que en la mayoría de los slams el uso de disfraces, tan prevalentes en lo carnavalesco, está prohibido; aún así, ambos actos comparten ideas y paralelismos interesantes. Los dos eventos son vistos como un espectáculo o función popular: "las fiestas públicas carnavalescas [...], la literatura paródica, vasta y multiforme, etc., poseen una unidad de estilo y constituyen partes y zonas únicas e indivisibles de la cultura cómica popular, principalmente de la cultura carnavalesca" (Bajtín, 2003: 4). Destacan también ambos como acontecimientos que se oponen "a la cultura oficial, al tono serio" (4) de modo verbal, pero que pueden también tener una base escrita. La oposición al tono serio que supone el slam ha sido resaltado en incontables ocasiones, y es uno de los rasgos que se esgrime más frecuentemente en su defensa como eje crucial de la poesía en vivo: “[e]s una forma más humana de ver la poesía, distinta a los Quevedos y Góngoras que conocemos de la literatura del colegio, y llena de gente fascinante" (Laura, 2012). Intrínsecamente conectado al rechazo de lo oficial por parte de estos acontecimientos y al vínculo con una gran masa de la población, se encuentra su oposición a lo que García Rodríguez ha denominado dentro del carnaval como "la perpetuación de jerarquías y valores" (García Rodríguez, 2013: 125). La cultura popular de la risa, ampliamente fomentada por numerosos slammers quizás como manera más directa de hacerse con el apoyo del público, ha sido vista por Bajtín y la mayoría de sus estudiosos como una forma de resistencia a los valores culturales de la clase dominante y como un fenómeno de des-jerarquización, una cuestión que ya hemos destacado también más arriba como fenómeno que se da en el slam tanto en relación a la homogeneización del público según Elam como en relación a la abolición de desigualdades cuando los asistentes pasan a formar parte de la actuación (Hoffman, 2013: 202-203). De este modo, se asiste durante estas funciones al "entrecruzamiento festivo de voces y cuerpos hacia la 
instalación transitoria de un mundo invertido, donde los/as marginados/as acceden al trono por un día" (García Rodríguez, 2013: 122). La des-jerarquización se extiende igualmente hasta la relación entre actores o poetas y espectadores, que se ha también tratado antes, ya que tal y como afirmaba Bajtín, "el carnaval ignora toda distinción entre actores y espectadores [...]. Los espectadores no asisten al carnaval, sino que lo viven" (Bajtín, 2003: 7). La vivencia del carnaval -y el slam- por parte de los espectadores radica en el carácter sincrético, ritual y heterogéneo del evento, así como en su praxis, ya que "presupone[n] la co-participación tanto de actores como de espectadores (que se mezclan) en acciones de signo crítico respecto a órdenes establecidos; se suprimen por un instante distancias sociales y se promueve un contacto libre y familiar entre las personas" (García Rodríguez, 2013: 122). En este punto converge también uno de los elementos más marcados sobre la risa popular que destacó Bajtín en su trabajo:

El autor satírico que sólo emplea el humor negativo, se coloca fuera del objeto aludido y se le opone, lo cual destruye la integridad del aspecto cómico del mundo; por lo que la risa negativa se convierte en un fenómeno particular. Por el contrario, la risa popular ambivalente expresa una opinión sobre un mundo en plena evolución en el que están incluidos los que ríen. (Bajtín, 2003: 11).

El conjunto de personas unidas por la risa, tal y como se puede observar en las performances de "iVámonos!" de Pablo Cortina, lo conforman no únicamente los miembros de la audiencia, sino que a ellos se une también el poeta que debe en ocasiones contener su propia risa para poder proseguir con la recitación del poema. Esta hilaridad que provoca la composición concilia puntos de vista y fomenta un sentimiento de comunidad absoluto en el que impera la poesía, lejos de una risa puramente satírica. En cuanto a la estética de esta poesía, el slam puede también coincidir en gran manera con lo que los estudiosos han destacado de los rasgos estéticos de la escritura o habla carnavalesca:

A contrapelo de lo grave y lo elevado, la carnavalización en el hablar instala -siempre transitoriamente- un tono pedestre, rústico, que sin embargo no elimina la posibilidad de determinado vuelo poético. Suele degradar lo abstracto. Reconoce la elegancia en el decir, pero también la desmitifica: la hace respirar y participar en el banquete. Un diálogo o encuentro carnavalizado, entonces, comulga con la vida mediante un rebajamiento que absorbe el mundo concreto al tiempo que lo renueva. Juega con el mundo. Lo adorna incluso, casi siempre de forma estrafalaria. Recomienza constantemente y no suscribe por supuesto grandes pretensiones espirituales (Mancuso, 2005: 126).

En el poema que se ha analizado de Cortina en las páginas anteriores, el público y los lectores pueden observar la carnavalización del habla a la que se refiere Mancuso. El tono prosaico de la composición no imposibilita la liricidad de los versos, y con gran garbo y desenvoltura se crean ritmos, cadencias, sonoridades y juegos de palabras que desembocan, infaliblemente, en una renovación estrafalaria del mundo (simio o simbólicamente simio) representado en el poema. Asimismo, las pretensiones espirituales de la composición se limitan a la creación de unos momentos de diversión que animen a la audiencia a participar y a pasárselo bien. Con ello, el slam, igual que lo carnavalesco, "no necesariamente [...] producirá prácticas revolucionarias, sino que, por el contrario, pueden ser simplemente prácticas de descompresión” (Mancuso, 2005: 104), cruciales en un evento de carácter social en el que deseen privilegiarse por encima de todo las relaciones entre los asistentes, en cualquiera de sus formas. 


\section{PUBLICIDAD Y MEDIOS DE COMUNICACIÓN}

Las cuestiones discutidas hasta aquí han querido demostrar que el slam no es ni una lucha ni un espectáculo lírico-bélico, y que encuadrarlo como tal supone limitar tanto sus funciones como su alcance literario y social. El uso que se ha hecho del lenguaje contendiente para referirse al slam puede vincularse al deseo de presentarlo "as an engaging performance, which is distinct from the mainstream poetry world", un hecho que "enables it to be packaged and branded as a marketable product, removed from the stigma which is perceived to plague public perceptions of poetry" (Gregory, 2008: 69). Exponerlo como un acto de moda ciertamente marketizable -algunos de los grupos de slam de la península ibérica han llevado a cabo sofisticadas campañas de publicidad que han popularizado aún más sus actividades- ${ }^{14}$ incide en su carácter social, no solo como un movimiento pensado para llegar a un amplio público, sino también como corriente que pervive gracias a su faceta social. Cabe resaltar en este punto que, más allá de su directa participación en los slams, el público lleva a cabo otro aspecto fundamental en estos eventos: los asistentes y seguidores de los poetry slams difunden estas actividades por las redes sociales, y forman una parte ineludible de la marketización de este producto cultural. De hecho, se ha resaltado en numerosas ocasiones que la amplia repercusión de la perfopoesía se debe en gran manera "a las redes sociales y a los nuevos medios de comunicación de masas" (García Villarán, 2012: 68), y que "compartir flujos de información nos ha permitido enriquecer la difusión de la poesía" (Montoto, 2012: 42), creando una red de redes que facilita la propagación de eventos y actividades. En este sentido, el poetry slam está incidiendo de manera muy positiva en la promoción de la poesía española, aportándole una visibilidad de la que carecería en caso contrario. La mencionada propagación tiene significativas implicaciones para su popularidad, por lo que el papel de su público adquiere un nuevo ángulo o función, y gana aún más protagonismo dentro del análisis de la slam poetry. Las tácticas de promoción y publicidad mencionadas hasta ahora ponen en evidencia la existencia de un receptor dual: los artículos o crónicas de prensa $-\mathrm{y}$ hasta cierto punto la distribución que se hace de ellos en las redes sociales- se dirigen a un público que no es necesariamente el que asiste a los slams -aunque puede serlo después de leer el texto-; y a este se une la audiencia asidua a los poetry slams. Este es un punto importante a tener en cuenta para entender la compleja relación existente entre el poetry slam, su audiencia y la representación que se hace de él fuera de sus círculos. Si resulta del todo imposible entender la poesía española actual sin el soporte de la red (Bagué Quílez y Santamaría, 2013: 29-30), también lo es racionalizar el lenguaje de las redes sociales sin incidir en la gran influencia de lo sensacionalista que existe en él: "We are simply suckers for the sensational" (Vista, 2015: 417). Así, la propia propagación de los eventos en la web por parte de slammers y seguidores -durante la cual se reenvían, retwittean y cuelgan las crónicas analizadas al principio del artículo que hacen uso de un conjunto de herramientas lingüísticas, retóricas y estéticas concretas- es en parte también culpable de la sensacionalización de los slams. Aunque el lenguaje usado por los usuarios de las redes no sea en sí mismo sensacionalista o bélico, sí lo es el de las noticias o crónicas que se dan a conocer a través de ellos, por lo que inciden y perpetúan estrategias y recursos dirigidos a la emotividad de lectores o usuarios, divulgando el poetry slam en cuantiosas ocasiones como

\footnotetext{
14 Véase, como ejemplo, el vídeo promocional que "Poetry Slam Madrid" realizó en el año 2016 para dar a conocer su labor y lo que es un poetry slam [último acceso 23 de enero de 2018].
} 
"duelos" o "luchas" en los que a su término perdura un solo contrincante. Scott Woods afirma que "[b]y dressing up poetry in the raiment of a fight or contest, it appeals to the modern taste for sensationalism in art without -when done right- delving into mere caricature or entertainment" (2008: 18), aunque debe remarcarse que, como se ha señalado en este artículo, en esta estrategia de marketing la estrecha línea que separa las definiciones ha resultado en ocasiones demasiado estrecha tanto para la prensa como para los propios grupos de poetry slam.

\section{CONCLUSIÓN: PUERTAS ABIERTAS DE PAR EN PAR PARA LA POESÍA ESPAÑOLA}

El análisis que se ha presentado en estas páginas ha querido evidenciar que la única lucha que debería asociarse con el poetry slam es su pelea constante para -y por encima de tododefender la poesía. Esta contienda o, mejor dicho, tal función, se ha convertido en un aspecto clave para la poesía española contemporánea, ya que con ella se consigue hacer llegar la poesía a una audiencia increíblemente amplia, ayudando a asegurar la continuidad del género. En un momento como el presente, en el que la lírica española -especialmente la de base performativagoza de gran dinamismo y vitalidad, debe aprovecharse la visibilidad colectiva para el género, y utilizarla para difundir la poesía española contemporánea de manera general. La obsesión de la prensa por fijar los slams poéticos como actos de belicismo -irónicamente positivo en cuanto a promoción del evento- supone una limitación en la concepción y entendimiento del acto performativo que se presenta, pero esta responde a un interés publicitario, y sería fácilmente rebatible con la existencia de estudios críticos y reflexivos del poetry slam. De la misma manera, el poetry slam, tan popular en todo el mundo, puede abrir fronteras a la poesía española del nuevo milenio: en el año 2016 Dante Alarido se clasificó en quinto lugar en el Campeonato Europeo de Poetry Slam representando "Poetry Slam España", y Margalida Followthelida, también representando a "Poetry Slam España" en el mismo campeonato, subió a la tercera posición del pódium en el 2017. Este reconocimiento internacional tan importante abre las puertas no sólo a la poesía performativa sino a la creación lírica general, cuyo ímpetu debería saberse explotar en un momento de tanta vitalidad lírica como el actual: "el slam es un instrumento maravilloso, si se sabe tañer" (Cortina, 2016: 81). El poetry slam, con la creación de un nuevo público, ofrece a la poesía española contemporánea un punto de apoyo primordial que debería cultivarse para fomentar su actividad -no sólo en cuanto a lo que se refiere a promoción, sino también en cuanto a la atención que se le dedica como producto cultural digno de estudio crítico. Un examen más sólido por parte de la crítica y el mundo académico sería una buena manera de contribuir a la continuación de los poetry slams y la salud del género lírico, y seguramente tal observación favorecería también un filtro de calidad para estos eventos. Aunque el cedazo de excelencia es ciertamente importante y muchos críticos han señalado o demostrado su recelo ante la calidad variable que puede tener un poetry slam, resulta necesario señalar también que hace falta aquí un método de estudio que no altere la dinámica de esta poesía y sus actos. Resulta igual de necesario un estudio que mantenga la risa festiva popular del acto, tan alejada de la risa puramente satírica y tan fundamental para el poetry slam. En otras palabras, se requiere una aproximación crítica y reflexiva que no cambie la relación simbiótica entre poeta y público, ni la democratización de la poesía que se encuentra en la base fundamental del slam y en su vocación de resistencia cultural. Sólo de esta manera se logrará destacar un acto -ahora sí- que supone una lucha feroz en defensa 
del género poético, y en el que tal y como pronunció Allan Wolf, los puntos son lo de menos; lo que importa es la poesía.

\section{BIBLIOGRAFÍA}

Abascal Vicente, María Dolores (2004). “Oralidad y retórica en el Barroco”. Aullón DE HARO, Pedro (Ed.). Barroco. Madrid: Verbum: 249-375.

Ahern, Kenneth R. y SOSYura, Denis. "Rumour Has It: Sensationalism in Financial Media". Review of Financial Studies 28(7) (2015): 2050-2093.

ANTÓN CRESPO, Margarita. "Comunicación Sensacionalista. La prensa del corazón en España". H-ermes: Journal of Communication 5 (2015): 31-53.

ArenAS, Paula (2011). "Batallas de rimas poéticas". 20 minutos (04/04./2011): s.p.

Bagué Quílez, Luis y SAntamaría, Alberto (2013). “2001-2012: una odisea en el tiempo”. Bagué QUílez, Luis y SANTAMARÍA, Alberto(Eds.). Malos tiempos para la épica: Última poesía española (2001-2012). Madrid: Visor.

BAjTín, Mijaíl Mijáilovich (2003). La cultura popular en la Edad Media y en el Renacimiento: El contexto de Francois Rabelais. Madrid: Alianza Editorial.

BARBER, David (2000). "The Man in the Back Row Has A Question: VI". The Paris Review 42(154) (2000): 370-402.

Berger, Javier (2012). "Perfopoesía... Cinco minutos y a escena”. MezQuita, Nuria y García Villarán, Antonio (Eds.). Perfopoesía: sobre la poesía escénica y sus redes. Sevilla: Cangrejo Pistolero Ediciones: 59-64.

BOudreau, Kathryn E. "Slam Poetry and Cultural Experience for Children". Forum on Public Policy 5(1) (2009): 1-15.

Cervantes SaAvedra, Miguel de (2004). Don Quijote de la Mancha. Madrid: Algaba Ediciones.

CHIVITE TORTOSA, Eduardo (2012). "Una retórica fronteriza: interacción y plasticidad". Mezquita, Nuria y García Villarán, Antonio (Eds.). Perfopoesía: sobre la poesía escénica y sus redes. Sevilla: Cangrejo Pistolero Ediciones: 72-83.

Cortina, Pablo (2016). Contra los 'Slammers': 12 partituras, un poema y un discurso. Madrid: Amargord.

CONBOY, Martin (2004). Journalism: A Critical History. Londres: SAGE.

Conboy, Martin (2006). Tabloid Britain: Constructing A Community Through Language. Nueva York: Routledge.

Cullell, Diana. “(Re-)Locating Prestige: Poetry Readings, Poetry Slams y Poetry Jam sessions in Contemporary Spain”. Hispanic Research Journal 16(6) (2015): 547-561.

ElAm, Keir (2002). The Semiotics of Theatre and Drama. Nueva York: Taylor \& Francis.

FAnjul, Sergio G. (2013). "Poetas contra raperos". El País (18.04.2013): s.p. 
FERNÁNDEZ, Saül (2012). "Duelo de poetas en los bares”. La Nueva España (15.03.2012): s.p.

GALlardo, Victoria (2015). "Duelo de versos". El Mundo (07.10.2015): s.p.

GARCía RODRÍGUEZ, Raúl Ernesto (2013). "La carnavalización del mundo como crítica: risa, acción política y subjetividad en la vida social y en el hablar”. Athenea Digital 13(2): 121-130.

García VILLARÁn, Antonio (2012). “¿Qué es esto de la perfopoesía?”. MEZQUiTA, Nuria y García Villarán, Antonio (Eds.). Perfopoesia: sobre la poesía escénica y sus redes. Sevilla: Cangrejo Pistolero Ediciones: 7-20.

GONZÁLEZ VALERO, Sergio (2013). "El club poético de la lucha”. El Metrópoli (11.10.2013): s.p.

Gregory, Helen. "The Quiet Revolution of Poetry Slam: the Sustainability of Cultural Capital in the Light of Changing Artistic Conventions". Ethnography and Education 3(1) (2008): 63-80.

GutiérReZ, Jaime (2014). "Cinco años de Poetry Slam en Madrid: de movimiento poético a 'tic nervioso"'. Rtve (16.06.2016): s.p.

Herzog, Werner (2011). "Introito. Poetry Slam: Una aventura". Herzog, Werner (Ed.). Poetry Slam: Antología. Poesía en escena. Madrid: Pigmalion Edypro: 9-11.

Hoffman, Tyler. "Treacherous Laughter: The Poetry Slam, Slam Poetry, and the Politics of Resistance". Studies in American Humor 8 (2001): 49-64.

Hoffman, Tyler (2013). American Poetry in Performance: From Walt Whitman to Hip Hop. Ann Arbor: University of Michigan Press.

Holman, Bob (2000). “The Room”. Mex Glazner, Gary (Ed.). Poetry Slam: The Competitive Art of Performance Poetry. San Francisco: Manic D Press: 15-21.

IGLESIAS LODARES, Gracia (2012). "Yo-poema. De la poesía a la performance, de la performance a la poesía”. Mezquita, Nuria y García villarán, Antonio (Eds.). Perfopoesía: sobre la poesía escénica y sus redes. Sevilla: Cangrejo Pistolero Ediciones: 47-58.

Kennedy, X. J. "Pleasure or Punishment: Hearing a Poet Read". Poets \& Writers Magazine 25 (1997): 70-77.

LAura (2012). "Poetry Slam de Madrid, otra forma de ver la poesía". Madridfree (07.06.2012): s.p.

Mancuso, Hugo (2005). La palabra viva. Teoría verbal y discursiva de Michail Bachtin. Buenos Aires: Paidós.

MANZANO FRANCO, Javier (2012). "En busca de los orígenes de la perfopoesía española. Juglares y trovadores en la transmisión del poema medieval". MEZQUITA, Nuria y GARCíA villarán, Antonio (Eds.). Perfopoesía: sobre la poesía escénica y sus redes. Sevilla: Cangrejo Pistolero Ediciones: 85-105.

MARTÍNEZ CANTÓN, Clara Isabel. "El auge de la nueva poesía oral. El caso del poetry slam". Castilla, Estudios de Literatura 3 (2012): 385-401. 
Mex Glazner, Gary (2000). "The Rules”. Mex Glazner, Gary (Ed.). Poetry Slam: The Competitive Art of Performance Poetry. San Francisco: Manic D Press: 13-14.

Mezquita, Nuria y García villarán, Antonio (Eds.) (2012). Perfopoesía: sobre la poesía escénica y sus redes. Sevilla: Cangrejo Pistolero Ediciones.

Montoto, Nacho (2012). "Perfopoesía: red de redes". Mezquita, Nuria y GARCía ViLLARÁn, Antonio (Eds.). Perfopoesía: sobre la poesía escénica y sus redes. Sevilla: Cangrejo Pistolero Ediciones: 41-46.

NovaK, Julia (2011). Live Poetry: An Integrated Approach to Poetry in Performance. Amsterdam: Rodopi.

NovAK, Julia. "Performing the Poet, Reading (to) the Audience: Some Thoughts on Live Poetry as Literary Communication". Journal of Literary Theory 6(2) (2012): 358-382.

ONG, Walter J. (1997). Oralidad y escritura: Tecnología de la palabra. San Diego, CA: Fondo de Cultura Económica.

OsunA, Inmaculada. "Justas poéticas en Granada en el siglo XVII: materiales para su estudio". Criticón 90 (2004): 35-77.

PÉREZ, Susana (2015). "Batalla de versos a micrófono abierto". Madridiario (05.11.2015): s.p.

QUinTO, Raül (2013). “La poesía después de Internet”. BAgUÉ QUÍLEZ, Luis y SANTAMARÍA, Alberto (Eds.). Malos tiempos para la épica: Última poesía española (2001-2012). Madrid: Visor: 193-206.

S.S. (2013). “Combate a verso libre”. El Metrópoli (12.03.2013): 4.

TEumA, Jonathan (2015). "Poetry Slam”. The Spanish Herald (02.05.2015): s.p.

ViSTA, Alvin. "Mass Media, the 'Sensational Message', and Metamorphic Truths". Telematics and Informatics 32 (2015): 416-423.

Woods, Scott. "Poetry Slams: The Ultimate Democracy of Art". World Literature Today 82(1) (2008): 18-19. 